OPEN ACCESS

Edited by:

Julie Lucifora,

Institut National de la Santé et de la

Recherche Médicale (INSERM),

France

Reviewed by:

Suzanne Faure-Dupuy, German Cancer Research Center

(DKFZ), Germany

Peter Revill,

Peter Doherty Institute for Infection

and Immunity, Australia

Christophe Ramière,

Hospices Civils de Lyon, France

${ }^{*}$ Correspondence:

María Mercedes Elizalde

melizalde@docente.ffyb.uba.ar

Specialty section:

This article was submitted to

Virology,

a section of the journal

Frontiers in Microbiology

Received: 14 August 2021 Accepted: 13 October 2021 Published: 04 November 2021

Citation: Elizalde MM, Tadey L, Mammana L, Quarleri JF, Campos RH and

Flichman DM (2021) Biological Characterization of Hepatitis $B$ virus Genotypes: Their Role in Viral Replication and Antigen Expression. Front. Microbiol. 12:758613. doi: 10.3389/fmicb.2021.758613

\section{Biological Characterization of Hepatitis B virus Genotypes: Their Role in Viral Replication and Antigen Expression}

\author{
María Mercedes Elizalde ${ }^{1,2 *}$, Luciana Tadey ${ }^{3}$, Lilia Mammana ${ }^{3}$, Jorge Fabián Quarleri, ${ }^{1,2}$, \\ Rodolfo Héctor Campos ${ }^{2,4}$ and Diego Martín Flichman ${ }^{1,2}$
}

${ }^{1}$ Instituto de Investigaciones Biomédicas en Retrovirus y Sida (INBIRS), CONICET, Universidad de Buenos Aires, Buenos Aires, Argentina, ${ }^{2}$ Consejo Nacional de Investigaciones Científicas y Técnicas (CONICET), Buenos Aires, Argentina, ${ }^{3}$ Unidad de Virología, Hospital de Infecciosas "Francisco J. Muñiz", Buenos Aires, Argentina, ${ }^{4}$ Departamento de Microbiología, Inmunología, Biotecnología y Genética, Cátedra de Virología, Facultad de Farmacia y Bioquímica, Universidad de Buenos Aires, Buenos Aires, Argentina

Hepatitis B virus (HBV) inter-host evolution has resulted in genomic diversification reflected in the existence of nine genotypes (A-I) and numerous subgenotypes. There is growing evidence that genotypes influence HBV natural history, clinical outcomes, and treatment response. However, the biological characteristics underlying these differences have not yet been established. By transfecting $\mathrm{HuH}-7$ cells with unit-length constructs of genotypes A2, B2, C1, D1, and F1b, we identified major differences in HBV replicative capacity and antigen expression across genotypes. Genotypes B2 and F1b showed a 2-fold increase in cccDNA levels compared to the other genotypes $(p<0.005)$. Genotype A2 expressed the lowest pgRNA levels, with a 70-fold decrease in relation to the other genotypes $(p<0.0001)$, while genotype B2 showed the lowest Precore RNA levels, with a 100-fold reduction compared to genotype A2 $(p<0.0001)$. The highest intracellular HBV DNA levels were observed for genotype B2 and the lowest for genotypes A2 and C1 $(p<0.0001)$. Regarding antigen expression, genotype F1b secreted the highest HBsAg levels and genotype D1 the lowest $(p<0.0001)$, while genotypes A2 and B2 showed the highest intracellular HBsAg levels $(p<0.0001)$. Interestingly, genotype $C 1$ secreted the highest HBeAg levels, while genotype A2 showed the highest intracellular levels $(p<0.0001)$. Finally, the analysis of the intra/extracellular antigen ratios revealed that most genotypes retained intracellularly $5-20 \%$ of the antigens, except the genotype A2 that retained $50 \%$ of the total expressed antigens. In conclusion, this study provides new insights into the biological characteristics of HBV genotypes, being the first study to comparatively analyze European ( $A$ and $D$ ) and Asian ( $B$ and $C$ ) genotypes with the Latin American ( $F$ ) genotype. The differences in HBV replication and antigen expression might contribute to understand the differential role of genotypes in pathogenesis.

Keywords: Hepatitis B virus, genotypes, characterization, viral replication, antigen expression 


\section{INTRODUCTION}

Hepatitis B virus (HBV) is a major human health problem worldwide, with approximately 296 million individuals chronically infected worldwide and up to 1 million people dying annually from HBV-related liver diseases, such as cirrhosis and hepatocellular carcinoma (HCC) (WHO Hepatitis B, 2017).

HBV is a small, enveloped DNA virus that replicates through an RNA intermediate. The HBV genome consists of a partially double-stranded relaxed circular DNA (rcDNA) of $3.2 \mathrm{~kb}$. After infection, host DNA enzymes repaired the rcDNA to generate a covalently closed circular DNA (cccDNA). The cccDNA serves as a transcriptional template for the different viral RNAs. The $3.5 \mathrm{~kb}$ pregenomic RNA (pgRNA) is the mRNA for the synthesis of polymerase and core proteins and the template for reverse transcription. The $3.5 \mathrm{~kb}$ Precore mRNA encodes the HBV e antigen ( $\mathrm{HBeAg})$. The $2.4 \mathrm{~kb}$ and $2.1 \mathrm{~kb}$ transcripts generate the large (LHBs), and medium (MHBs), and small (SHBs) envelope proteins (HBsAg), respectively, while the $0.7 \mathrm{~kb}$ transcript encodes the regulatory $\mathrm{X}$ protein $(\mathrm{HBX})$. In the cytoplasm, core protein subunits assemble pgRNA and viral polymerase to form immature core particles. Once encapsidated, pgRNA is retrotranscribed by the polymerase, and mature rcDNA-containing virions are enveloped and released from the infected hepatocytes (Tsukuda and Watashi, 2020). Alternatively, the rcDNA-containing capsids can re-enter the nucleus through a recycling pathway to replenish the pool of cccDNA. In addition to virions, infected hepatocytes also released filamentous and spherical subviral particles composed primarily of HBsAg proteins (Caballero et al., 2018).

Based on its genetic divergence, $\mathrm{HBV}$ has been classified into 9 genotypes (A to I) and numerous subgenotypes. The genotypes (gt) and subgenotypes show different geographical distribution in populations around the globe (Kramvis, 2014; Tong and Revill, 2016). The most cosmopolitan genotypes are A and D, predominant in Europe, Africa, and North America. Genotypes B and C are most frequent in East and South-East Asia, and genotype $\mathrm{E}$ is mostly restricted to Africa. Genotype $\mathrm{F}$ is autochthonous from the American continent and found in native populations from Alaska, Central, and South America (Shi et al., 2013; Ledesma et al., 2015; Mojsiejczuk et al., 2020).

There is growing evidence that HBV genotypes influence clinical outcomes, $\mathrm{HBeAg}$ seroconversion rates, severity of liver disease, emergence of mutants, transmission patterns, and response to interferon therapy (Kim et al., 2011; Liu and Kao, 2013). It has been shown that patients infected with genotype A or B generally respond better to interferon treatment than patients infected with genotypes $\mathrm{C}$ and $\mathrm{D}$. In addition, individuals infected with (sub)genotypes $\mathrm{C}$ and F1b showed a delayed HbeAg to anti-Hbe seroconversion than those infected with (sub)genotypes A, B, D, and F4. Moreover, growing evidence has shown a close association of (sub)genotypes $\mathrm{C}$ and F1b with an early and rapid progression of chronic infection and evolution to HCC (Ching et al., 2016; Marchio et al., 2018; Pineau et al., 2018). However, there is a paucity of data regarding their distinctive biological characteristics, in particular for genotype F, due mainly to the limited geographic distributions of the genotypes.
The majority of studies comparing HBV genotypes have been restricted between genotypes B and C in Asia and genotypes $\mathrm{A}$ and $\mathrm{D}$ in Europe. In addition, there have been very few in vitro studies directly comparing virological parameters across genotypes due to a lack of appropriate replication models (Wose Kinge et al., 2020). Most studies have used more than unit-length HBV constructs. However, in these constructs, the complete $\mathrm{HBx}$ open reading frame and the enhancer I/II regions are duplicated. In addition, more than unit-length HBV constructs are directly transcribed in the cell nucleus bypassing the formation of cccDNA replicative intermediate (Amir et al., 2019). Hence, the utilization of these constructs may not be ideal to study differences in HBV replication and protein expression among genotypes. The use of unit-length monomeric constructs without heterologous promoters represents a better alternative due to the absence of duplicated genome regions and the ability of cccDNA formation.

In the present study, by transfecting $\mathrm{HuH}-7$ cells with unitlength monomeric constructs of the most prevalent genotypes in Asia, Europe, and Latin America, we comparatively analyze viral RNA transcription, genome replication, and protein expression across genotypes.

\section{MATERIALS AND METHODS}

\section{Viral Constructs}

Vector pUC19 containing full-length genomes of HBV genotypes $\mathrm{A} 2, \mathrm{~B} 2, \mathrm{C} 1, \mathrm{D} 1$, and F1b were constructed for this study. Briefly, HBV DNA was extracted from serum samples of $\mathrm{HBeAg}$-positive chronically infected patients. The characteristics of the patients from whom the serum samples were obtained are shown in Supplementary Table 1. Full-length HBV genomes were amplified adapting the method described by Günther, including $N d e \mathrm{I} / B s p \mathrm{QI}$ sites in $\mathrm{P} 1$ sense primer: 5'-CCGGACATATGATGCTCTTCTTTTTCACCTCTGCCTAA TCATC-3', and SacI/BspQI sites in $\mathrm{P} 2$ antisense primer (5'-CCGGAGAGCTCATGCTCTTCAAAAA GTTGCATGGTG CTGGTG-3'). Polymerase chain reactions (PCR) were performed using the Expand high-fidelity PCR system (Roche, Mannheim, Germany) according to the manufacturer's instructions.

The amplified HBV DNAs were digested with NdeI and SacI restriction enzymes (New England Biolabs, Beverly, MA, United States). The $3.2 \mathrm{~kb}$ fragments were separated by agarose gel electrophoresis, recovered by gel purification using the PureLink Quick Gel Extraction Kit (Invitrogen, Carlsbad, CA, United States), and inserted into NdeI/SacI sites of pUC19 vector. After cloning, constructs were sequenced in order to confirm the absence of mutations that might influence HBV replication and/or protein expression.

The subgenotypes used in the present study were selected according to the following criteria: the most widely distributed of their respective genotypes and the best characterized in previous studies (Velkov et al., 2018; Araujo et al., 2020; McNaughton et al., 2020). 
Subsequently, among the 242 positive samples for $\mathrm{HBsAg}$ and HBeAg (A2: 53, B2: 16, C1: 17, D1: 48 and F1b: 108) available in our sample bank, those closest phylogenetically to the consensus of each subgenotype obtained from the HBVdb database ${ }^{1}$ were cloned. Sequences containing deletions, mutations associated with $\mathrm{HBeAg}$ loss, or antiviral treatment were excluded from the analysis.

The GenBank accession numbers for these constructs were as follows: OK106253 (genotype A2), OK106254 (genotype B2), OK106255 (genotype C1), OK106256 (genotype D1), and OK106257 (Genotype F1b).

\section{Cell Culture and Transfection}

Human hepatoma cell lines HuH-7 (JCRB Cell Bank \#0403) and HepG2 (ATCC HB-8065) were grown in Dulbecco's modified Eagle's medium (DMEM; Sigma, CA, United States) supplemented with $10 \%$ fetal bovine serum (Sigma, CA, United States), $1 \mathrm{~mm}$ nonessential amino acids (GIBCO, Carlsbad, CA, United States), $2 \mathrm{~mm}$ L-glutamine (GIBCO, Carlsbad, CA, United States), $0.15 \%$ sodium bicarbonate, $100 \mathrm{UI} / \mathrm{ml}$ penicillin, and $100 \mu \mathrm{g} / \mathrm{ml}$ streptomycin at $37^{\circ} \mathrm{C}$ with $5 \% \mathrm{CO}_{2}$.

Full-length linear HBV DNAs (nt 1820-1820) with sticky ends were used for transfections. As previously described, linear HBV monomers were excised from the plasmids by restriction enzyme digestion with $5 \mathrm{U}$ of $B s p \mathrm{QI}$ (New England Biolabs, Beverly, MA, United States) at $50^{\circ} \mathrm{C}$. The $3.2 \mathrm{~kb}$ fragments were gel purified with PureLink Quick Gel Extraction Kit (Invitrogen, Carlsbad, CA, United States), according to the manufacturer's instructions, and the DNA was quantified by spectrometry (Elizalde et al., 2019). In order to mimic viral variability, a mix of 10 to 20 clones (pUC19-full-length HBV genomes) of each genotype were used in all experiments.

Cells were seeded to semi confluence in 6- or 24-well plates and transfected with $1 \mu \mathrm{g}$ of full-length HBV DNAs for 6-well plates and $0,25 \mu \mathrm{g}$ for the 24 -well plates. Transient transfections were carried out using X-tremeGene ${ }^{\mathrm{TM}} 9$ transfection reagent (Roche, Mannheim, Germany), according to the manufacturer's recommendations. The cells were maintained at $37^{\circ} \mathrm{C}$ in $5 \%$ $\mathrm{CO}_{2}$ atmosphere. After $6 \mathrm{~h}$, the medium was replaced, and the cultures were incubated for $72 \mathrm{~h}$. In experiments to evaluate cccDNA recycling, cells were treated with $100 \mu \mathrm{m}$ Lamivudine throughout the assay.

In all experiments, $0.05 \mu \mathrm{g}$ of the luciferase reporter vector pGL4.13 (luc2/SV40; Promega, Madison, WI, United States) was co-transfected with the linear full-length HBV genomes as transfection efficiency control. To evaluate the light emission produced by the luciferase activity, $20 \mu \mathrm{l}$ of cell lysates was mixed with the commercial reagent Luciferase Assay System (Promega, Madison, WI, United States), according to the manufacturer's recommendations, and relative light units were detected. Results were expressed per relative light units.

${ }^{1}$ https://hbvdb.lyon.inserm.fr/HBVdb/HBVdbIndex

\section{Analysis of Covalently Closed Circular DNA}

The quantification of HBV cccDNA was performed by quantitative real-time PCR (qPCR). Briefly, $72 \mathrm{~h}$ post-transfection, cells were treated with lysis buffer containing $50 \mathrm{~mm}$ Tris- $\mathrm{HCl}(\mathrm{pH} \mathrm{8})$, $10 \mathrm{~mm}$ EDTA, $100 \mathrm{~mm} \mathrm{NaCl}, 0.5 \%$ SDS, and $0.5 \mathrm{mg} / \mathrm{ml}$ proteinase $\mathrm{K}$ (Invitrogen, United States) and incubated at $56^{\circ} \mathrm{C}$ for $2 \mathrm{~h}$. Nucleic acids were purified by phenol-chloroform extraction and ethanol precipitation. Isolated intracellular total DNA was treated with $500 \mathrm{U} / \mathrm{ml}$ of T5 exonuclease (New England Biolabs, Beverly, MA, United States) at $37^{\circ} \mathrm{C}$ for $1 \mathrm{~h}$ to remove non-supercoiled dsDNA. Samples were subjected to qPCR using Luna Universal qPCR Master Mix (2x; New England Biolabs, Beverly, MA, United States). Selective cccDNA primers: sense 5'-GTCTGTTCCTTCTCATCTGC-3' (nt 1551-1570) and antisense 5'-AGGCACAGCTTG GTGGCTTG-3' (nt 1887-1868) were used for the qPCR. Mitochondrial DNA was analyzed as an internal reference to normalized cccDNA levels. The primers for detection of mitochondrial DNA were as follows: sense $\quad 5^{\prime}$-CCCCACAAACCCCATTACTAAACCCA- $3^{\prime}$ and antisense $5^{\prime}$-TTTCATCATGCGGAGATGTTGGATGG-3' ${ }^{\prime}$. Serial dilutions of a HBV replication-competent plasmid (pCH-9/3091) were used as quantification standards. HBV DNA extracted from serum samples of $\mathrm{HBeAg-positive} \mathrm{patients} \mathrm{with} \mathrm{a} \mathrm{viral}$ load of $8.2 \log 10 \mathrm{IU} / \mathrm{ml}$ was used as a control to evaluate the efficacy of DNase treatment and the specificity of the cccDNA amplification.

\section{Analysis of HBV RNA}

Precore mRNA and pgRNA were quantified by RT-qPCR. Total cellular RNA from transfected cells was extracted with TRIzol reagent (Invitrogen, Carlsbad, CA, United States). RNA samples were treated with RQ1 RNase-free DNase (Promega, Madison, WI, United States) at $37^{\circ} \mathrm{C}$ for $1 \mathrm{~h}$, to remove DNA. Concentration and purity of RNA were determined by spectrometry. One microgram of RNA was reverse-transcribed into cDNA with Random Hexamer Primers (Biodynamics, Buenos Aires, Argentina) using M-MLV reverse transcriptase (Promega, Madison, WI, United States). Then Precore mRNA and pgRNA were quantified as previously described (Laras et al., 2002, 2006). Briefly, the cDNA product was used in two separate amplification reactions with a common antisense primer: 5'-GGAAAGAAGTCAGAAGGCAA-3' (nt 1974-1955), and sense primers: 5'-GGTCTGCGCACCAGCACC-3' (nt 1796-1813) for the specific detection of Precore mRNA transcripts and 5'-CACCTCTGCCTAATCATC-3' (nt 1826-1843) primer for detecting total Core Promoter directed transcription. The levels of pgRNA transcripts were calculated by subtracting Precore mRNA levels from total Core Promoter directed transcription. Amplification of GAPDH cDNA was used as housekeeping gene to normalize the mRNA levels. Primers used for GAPDH mRNA amplification were as follows: sense 5'-GAAGGTGAAGG TCGGAGTC-3' and antisense 5'-GAAGA TGGTGATGGG ATTTC-3'. For quantification, serial dilutions of an HBV replication-competent plasmid were used as standards. 
To rule out amplification of contaminating DNA, PCR amplification was also routinely performed without reverse transcriptase.

HBV replicative activity (replication fitness) was expressed as pgRNA/cccDNA ratio, while Precore mRNA/cccDNA ratio was used to assess $\mathrm{HBV}$ transcriptional efficiency.

\section{Analysis of Intracellular HBV DNA}

HBV replicative intermediates were analyzed by Southern blot. Briefly, $72 \mathrm{~h}$ post-transfection, cells were treated with lysis buffer (50 mm Tris/ $\mathrm{HCl} \mathrm{pH} \mathrm{7.5;100} \mathrm{mm} \mathrm{NaCl;} 1 \mathrm{~mm}$ EDTA; 0.5\% $\mathrm{NP} 40$ ) and centrifuged $1 \mathrm{~min}$ at $14,000 \mathrm{rpm}$ to remove the nuclei. The supernatants were collected and treated with $0.5 \mathrm{mg} /$ $\mathrm{ml}$ proteinase $\mathrm{K}$ (Invitrogen, Carlsbad, CA, United States) at $56^{\circ} \mathrm{C}$ for $2 \mathrm{~h}$. Nucleic acids were purified by phenol-chloroform extraction and ethanol precipitation in the presence of $20 \mu \mathrm{g}$ of dextran. DNA isolated from cell lysates was separated on a $1 \%$ agarose gel and blotted onto a nylon-positive membrane (Roche, Mannheim, Germany). The transferred DNA was immobilized by an ultraviolet crosslinker and hybridized with a subgenomic digoxigenin (DIG)-labelled probe (Roche, Mannheim, Germany) of each genotype. The hybridization signals were detected on an X-ray film using an enzyme-linked immunoassay (DIG Luminescent Detection Kit; Roche, Mannheim, Germany) and were quantified with the ImageJ software (Wayne Rasband, NIH, United States).

\section{Analysis of Extracellular HBV DNA}

Viral progeny was quantified by qPCR. Seventy-two hours posttransfection, cell culture supernatants were harvested and clarified by centrifugation at $3,000 \mathrm{~g}$ for $10 \mathrm{~min}$. Supernatants were treated with lysis buffer (50 mm Tris- $\mathrm{HCl} \mathrm{pH} \mathrm{7.5;} 1 \mathrm{~mm}$ EDTA; 1\% SDS; $0.5 \mathrm{mg} / \mathrm{ml}$ proteinase $\mathrm{K}$ (Invitrogen, United States)) and incubated at $56^{\circ} \mathrm{C}$ for $2 \mathrm{~h}$. Nucleic acids were purified by phenol-chloroform extraction and ethanol precipitation in the presence of $20 \mu \mathrm{g}$ of dextran. qPCR was performed in a Step One Plus Real-Time PCR System (Applied Biosystems, Foster City, CA, United States) using Luna Universal qPCR Master Mix (2x; New England Biolabs, Beverly, MA, United States). The following primers were used for the amplification: sense 5'-ATGGAGACCACCGT GAACGC-3' (nt 1608-1627) and antisense 5'-AGGCACAGCTTG GTGGCTTG-3' (nt 1887-1868). To avoid amplification of the input linear HBV DNA used for transfection, primers that specifically amplify relaxed circular HBV DNA were used (Elizalde et al., 2019). Serial dilutions of an HBV replication-competent plasmid (pCH-9/3091) were used as quantification standards.

\section{Antigen Quantification}

The HBsAg concentration in cell lysates and cell culture supernatants was measured by electrochemiluminescence immunoassay (ECLIA) using the Elecsys HBsAg II quant II on a Cobas e801 instrument (Roche, Mannheim, Germany), according to the instructions of the manufacturer. Results were expressed in $\mathrm{IU} / \mathrm{ml}$. The $\mathrm{HBeAg}$ concentration in cell lysates and culture supernatants was measured using the Elecsys HBeAg on a Cobas e801 instrument (Roche, Mannheim, Germany), according to the manufacturer's recommendations. Results were expressed in Sample/Cut off value (S/CO).

The linearity dynamic range of the assay was validated making serial dilutions of serum samples with known HBeAg levels.

To rule out the possibility of cross-reactivity of the core protein and HBeAg, HuH-7 cells were transfected with a fulllength HBV genome harboring the G1896A Precore mutation. Furthermore, the possible interference of the intracellular cell lysate in the specificity of the assay was evaluated by challenging serum samples with known HBeAg or qHBsAg levels diluted with non-transfected cell lysates.

\section{Western Blot Analysis}

For intracellular HBV surface proteins, cells were lysed in 1\% Triton, $20 \mathrm{~mm}$ Tris, $1 \mathrm{~mm}$ EDTA, $150 \mathrm{~mm} \mathrm{NaCl}$, and protease inhibitor cocktail (Sigma, United States). For extracellular proteins, cell culture supernatants were used directly. Samples were mixed in Laemmli buffer, boiled, loaded on $12 \%$ SDS-polyacrylamide gels, and transferred to PVDF membranes (Hybond, GE Healthcare, UK), according to standard protocols. The membranes were blocked in 5\% non-fat milk in Trisbuffered saline (20 mm Tris and $150 \mathrm{~mm} \mathrm{NaCl}, \mathrm{pH} 7.6)$ containing $0.1 \%$ Tween-20 for $1 \mathrm{~h}$ at room temperature. HBV surface proteins were detected using anti-SHBs (HB01) monoclonal antibody (kindly provided by Prof. Aurelia Zvirbliene, Lithuania). Peroxidase-conjugated secondary antibodies were purchased from Santa Cruz Biotechnology (United States). Protein-specific bands were visualized using an enhanced chemiluminescence (ECL) system (GE Healthcare, UK) by autoradiography. The quantification was performed using Image J analysis software (Wayne Rasband, NIH, United States). $\beta$-actin detection was used as intracellular protein loading control.

\section{Statistical Analysis}

All experiments were performed independently three times. Statistical significance was determined by one-way ANOVA followed by post hoc Turkey's test. A value of $p<0.005$ was considered statistically significant. Results were expressed as mean \pm standard deviation. All analyses were performed using GraphPad Prism 8 software (GraphPad Software, San Diego, CA, United States).

\section{RESULTS}

\section{HBV Replicative Capacity Varied Distinctly Across Genotypes}

To comparatively analyze the replication capacity among HBV genotypes, three days post-transfection, cells and culture supernatants were harvested, and levels of cccDNA, viral RNA, intracellular HBV DNA, and secreted virion DNA were examined.

\section{Covalently Closed Circular DNA}

Significant differences were observed in cccDNA levels among genotypes. As shown in Figure 1, genotypes B2 and F1b showed 


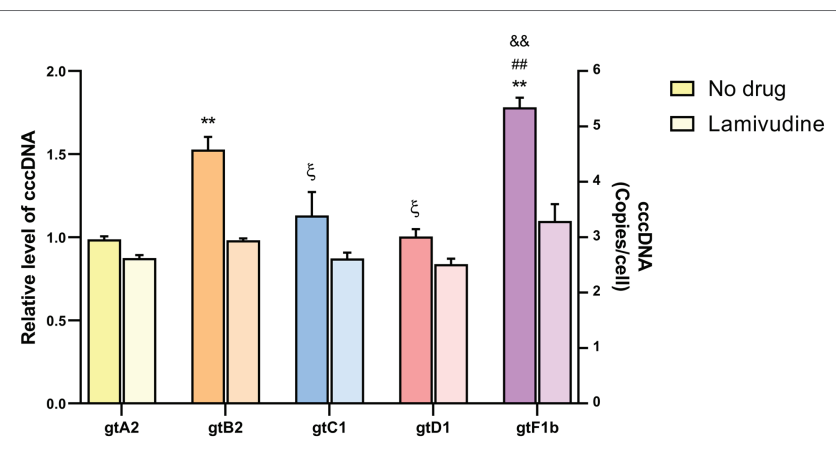

FIGURE 1 | Analysis of cccDNA levels among genotypes. HuH-7 cells were transfected with linear full-length HBV genomes of genotypes A2, B2, C1, D1, and $\mathrm{F} 1 \mathrm{~b}$ in the presence or in the absence of $100 \mu \mathrm{m}$ Lamivudine. 3 days posttransfection, cells were harvested, total DNA was extracted, and cccDNA levels were assessed by qPCR. Results were normalized to mitochondrial DNA. Shown values represent the mean \pm standard deviation of three independent experiments. *: statistical difference in relation to gtA2, $\xi$ : difference in relation to gtB2, \#: difference in relation to gtC1 and \&: difference in relation to gtD1. One symbol: $p<0.005$ and two symbols: $p<0.0001$.

an approximately 2-fold increase compared to genotypes A2, $\mathrm{C} 1$, and D1 $(p<0.005$, in comparison with genotype A2). In all cases, the values were normalized to those of genotype A2.

In order to assess whether cccDNA recycling was involved in the observed differences in cccDNA levels among genotypes, transfection assays were performed in the presence of $100 \mu \mathrm{m}$ Lamivudine to inhibit reverse transcription, formation of new rcDNA, and replenish of cccDNA pool (Kock et al., 2003). Lamivudine treatment reduced extracellular HBV DNA levels by more than 99\% (Supplementary Figure 1). Interestingly, cccDNA levels were similar among genotypes in the presence of Lamivudine, in contrast to the differences observed in the absence of the antiviral (Figure 1). This result suggests that the differences in cccDNA levels across genotypes might be related to an unequal recycling capacity among HBV genotypes.

\section{HBV RNA}

The pgRNA levels also revealed notable differences among genotypes (Figure 2A). Genotype A2 expressed the lowest levels of pgRNA transcripts, while genotypes C1, D1, and particularly genotypes B2 and F1b expressed the highest levels of pgRNA, with an increase of more than 70 times in relation to genotype A2 $(p<0.0001$, in comparison with genotype A2). Whereas Precore mRNA levels showed that genotypes A2 and D1 expressed the highest levels, while genotypes B2 and C1 presented the lowest levels, with a reduction of more than 100 -fold compared to genotype A2 $(p<0.0001$, in comparison with genotype A2; Figure 2B).

These results showed a notable imbalance in the transcription of the RNAs regulated by the Core Promoter. In some genotypes (B2, C1, and F1b), pgRNA levels exceed Precore mRNA by more than two orders of magnitude, while in other genotypes (A2 and D1), the pgRNA/Precore mRNA ratio was significantly lower.

In addition, the pgRNA/cccDNA ratio revealed that pgRNA levels reflected the replicative activity of the cccDNA, which is a very low replicative activity for genotype A2, compared to the other genotypes $(p<0.0001$, in comparison with genotype A2; Figure 2C). On the other hand, regarding the Precore mRNA/cccDNA ratio, genotypes $\mathrm{B} 2$ and $\mathrm{C} 1$ showed the lowest transcriptional activity of the cccDNA, while genotypes A2 and D1 presented the highest transcriptional activity $(p<0.0001$, in comparison with genotype A2; Figure 2D).

\section{HBV DNA}

The analysis of intracellular HBV DNA intermediates also revealed marked differences between genotypes (Figures 3A,B). The highest levels were observed for genotype B2 $(p<0.0001$, in comparison with genotype A2), reflecting similar findings for cccDNA and pgRNA. In contrast, the lowest DNA levels were detected for genotypes A2 and $\mathrm{C} 1(p<0.0001$, in comparison with genotype A2). For genotype A2, this result is in line with cccDNA and pgRNA levels. Whereas for genotype C1, intracellular DNA levels correspond to those of cccDNA, but did not mirror pgRNA levels.

Interestingly, the notable differences in the levels of cccDNA, pgRNA, and intracellular HBV DNA were not strictly reflected in the extracellular HBV DNA levels. No significant differences were observed in the extracellular HBV DNA levels in relation to genotype A2 (Figure 3C). Additionally, similar findings were also obtained when these clones were transfected in HepG2 cells (Supplementary Figure 2).

\section{HBV Protein Expression and Secretion Differ Among Genotypes}

To comparatively analyze the expression and secretion of HBV proteins across genotypes, cells and culture supernatants were harvested from transfected cells and the intra- and extracellular levels of HBsAg and HBeAg were determined.

\section{HBsAg}

At the extracellular level, genotype F1b secreted the highest HBsAg levels, whereas genotype D1 secreted significantly lower levels $(p<0.0001$, in comparison with genotype A2). In contrast, the analysis of intracellular HBsAg revealed that genotypes A2 and B2 expressed the highest levels, while genotypes C1, D1, and F1b showed the lowest levels $(p<0.0001$, in comparison with genotype A2; Figure 4A). Regardless of the absolute amount of HBsAg, it is worth noting the differences in the ratio of HBsAg expression and secretion across genotypes. While genotype F1b secreted more than $90 \%$ of the antigen, genotypes A2 and D1 retained approximately $50 \%$ of the total protein in the cells (Figure 4B). Similar patterns of HBsAg expression and secretion across genotypes were also observed after transfection in HepG2 cells (Supplementary Figure 3). As in the evaluation of viral replication, the mean value of genotype A2 was used to normalize the samples.

In order to further characterize HBsAg expression among genotypes, the relative abundance of the different surface proteins (LHBs, MHBs, and SHBs) was determined. For all genotypes, it was observed that SHBs $(24$ and $27 \mathrm{kDa}$ ) represented the major fraction of HBsAg, both intra- and extracellularly (Figure 5). However, the relative amount of LHBs/MHBs 
A

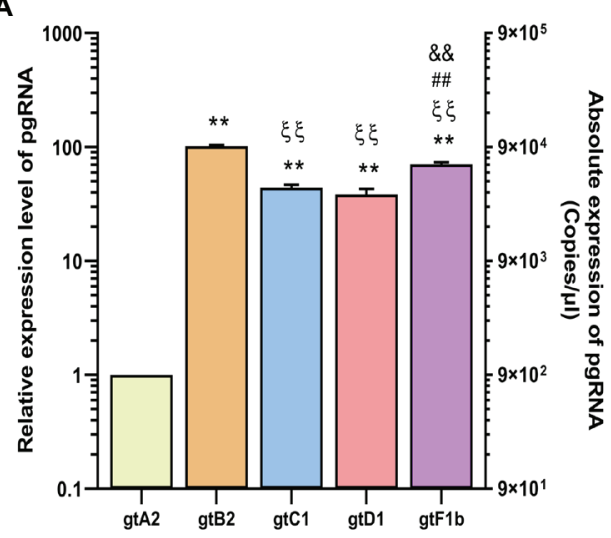

C

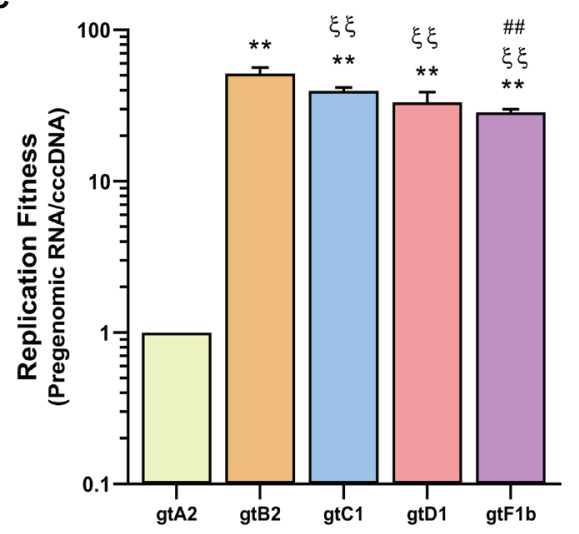

B

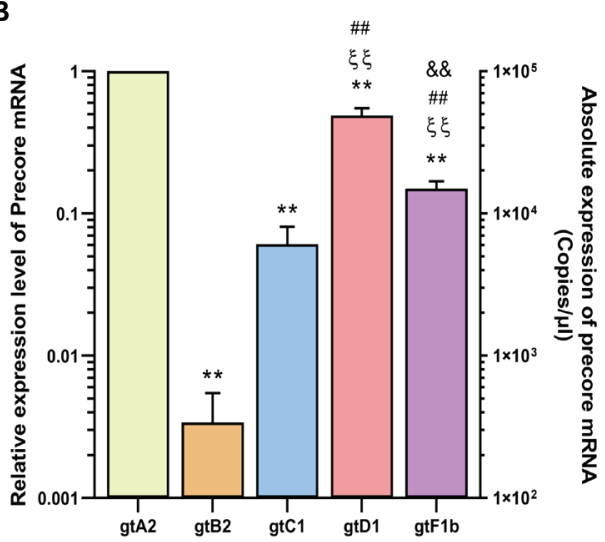

D

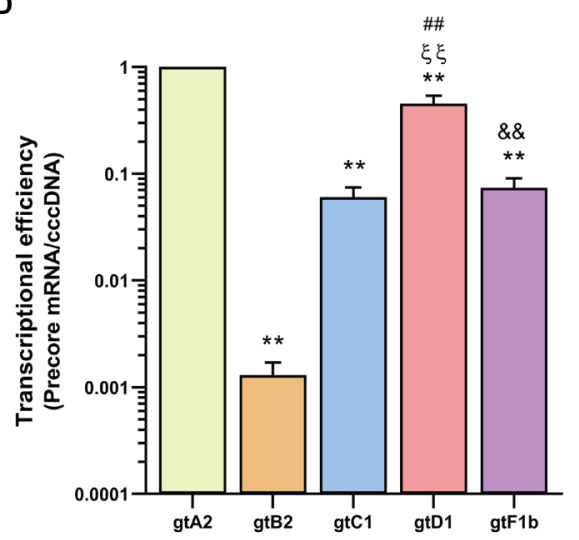

FIGURE 2 | Analysis of HBV RNA levels across genotypes. HuH-7 cells were transfected with linear full-length HBV genomes of genotypes A2, B2, C1, D1, and F1b. Three days post-transfection, cells were harvested, total RNA was extracted, and pgRNA (A) and Precore mRNA (B) levels were analyzed by transcript-specific RT-qPCR. (C) cccDNA replicative activity was determined as molecules of pgRNA synthesized per cccDNA (pgRNA/cccDNA). (D) The number of Precore mRNA transcripts produced per cccDNA (Precore RNA/HBVccc) was used to assess HBV transcriptional efficiency. Values shown represent the mean \pm standard deviation of three independent experiments. *: difference in relation to gtA2, $\xi$ : difference in relation to gtB2, \#: difference in relation to gtC1 and \&: difference in relation to gtD1. Two symbols: $p<0.0001$.

compared to SHBs was higher for genotype D1 (>30\%) in comparison with the rest of the genotypes $(<23 \%)$. Regarding the relative amount of LHBs (42 and $39 \mathrm{kDa}$ ) and MHBs (36 and $33 \mathrm{kDa}$ ), no significant differences were observed across genotypes in cell lysates; however, in the supernatants, a greater amount of MHBs than LHBs was observed for genotypes A2, $\mathrm{B} 2, \mathrm{C} 1$, and D1, while for genotype F1b, this ratio was inverted.

\section{$\mathrm{HBeAg}$}

The extracellular $\mathrm{HBeAg}$ analysis showed that genotype $\mathrm{C} 1$, one of the lowest replicators, secreted the highest levels, followed by genotypes B2 and A2, while genotypes D1 and F1b secreted the lowest levels of HBeAg $(p<0.0001$, in comparison with genotype A2). On the contrary, the intracellular $\mathrm{HBeAg}$ analysis revealed that genotype A2 expressed significantly higher levels in relation to the rest of the genotypes $(p<0.0001$, in comparison with genotype A2; Figure 6A). Furthermore, the evaluation of the intra/extracellular $\mathrm{HBeAg}$ ratio showed that most genotypes retained $10-20 \%$ of the antigen in the cells, except for genotype A2 which retained $50 \%$ of the protein intracellularly (Figure 6B).
In a similar way, comparable levels of intra- and extracellular HBeAg were detected in HepG2 cells (Supplementary Figure 4).

To rule out the possibility of cross-reactivity of the core protein and $\mathrm{HBeAg}, \mathrm{HuH}-7$ cells were also transfected with a full-length HBV genome harboring the G1896A Precore mutation that abrogates $\mathrm{HBeAg}$ expression. Intra- and extracellular $\mathrm{HBeAg}$ was not detected in the Precore mutant (Supplementary Figure 5), indicating that there is no cross-reactivity between HBV core protein and HBeAg in the ECLIA assay.

Taken together, these results showed that HBV genotypes differ in their replication capacity, as well as in their protein expression and secretion. As a summary, the overall expression of each genotype is shown in Table $\mathbf{1}$.

\section{DISCUSSION}

The HBV replication hinges on a finely poised and complex interplay between several viral factors, including viral genotypes. There is growing evidence that HBV genotypes differ in clinical 

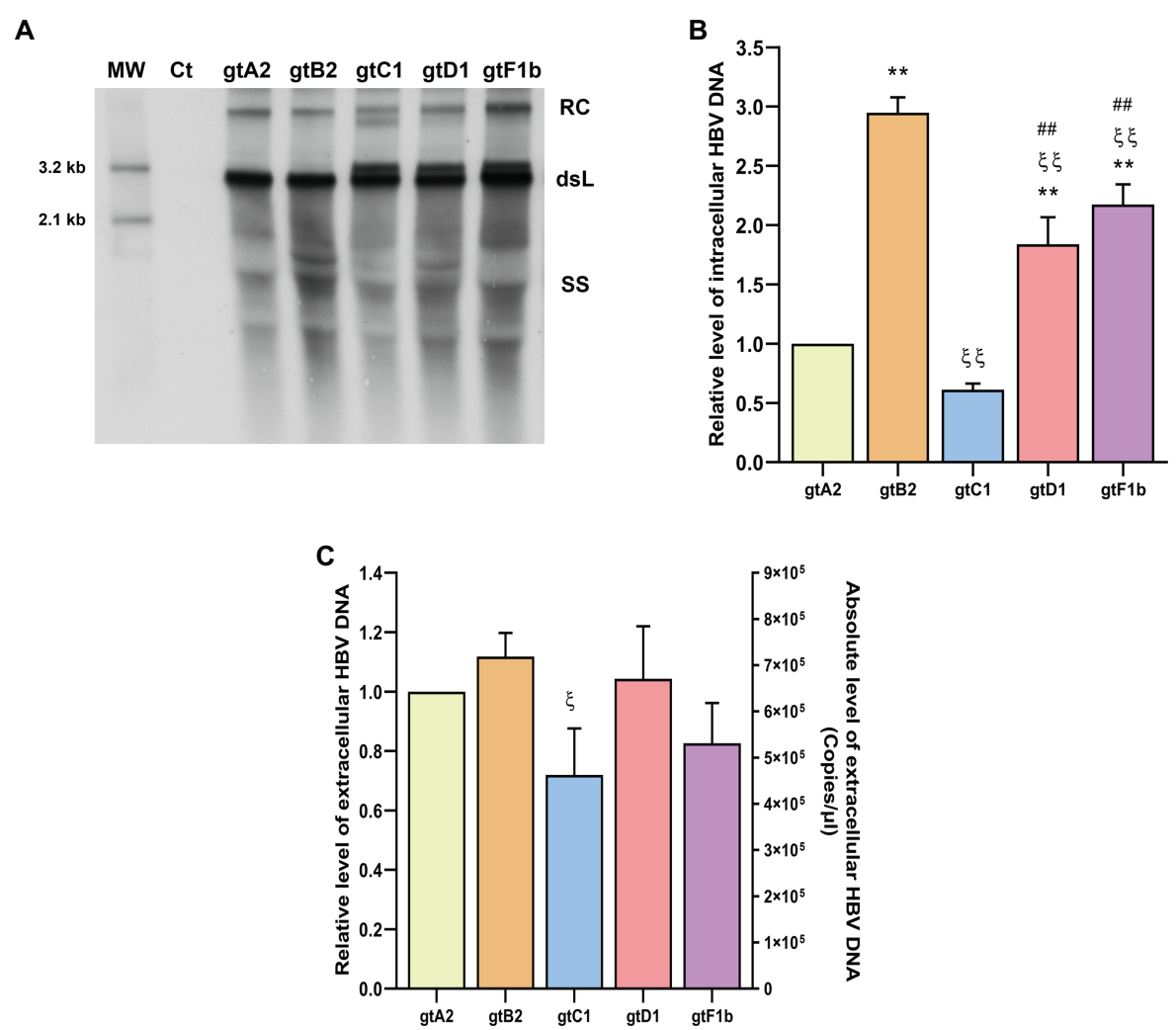

FIGURE 3 | Analysis of HBV DNA levels among genotypes. HuH-7 cells were transfected with linear full-length HBV genomes of genotypes A2, B2, C1, D1, and F1b. Three days post-transfection, cells and culture supernatants were harvested. (A) HBV DNA replicative intermediates were assessed by Southern blot analysis. Ct: cell transfected with pUC19 empty vector (control); RC: HBV relaxed circular DNA; dsL: HBV double-stranded linear DNA; SS: HBV single-stranded DNA. (B) Relative intensity of the SS band was quantified using ImageJ software. The band corresponding to the dsL HBV DNA was not included in the quantitative analysis because this DNA may be partially derived from transfected input DNA. (C) HBV extracellular DNA levels were determined by qPCR. Shown values represent the mean \pm standard deviation of three independent experiments. *: difference in relation to gtA2, $\xi$ : difference in relation to gtB2, \#: difference in relation to gtC1 and \&: difference in relation to gtD1. One symbol: $p<0.005$ and two symbols: $p<0.0001$.
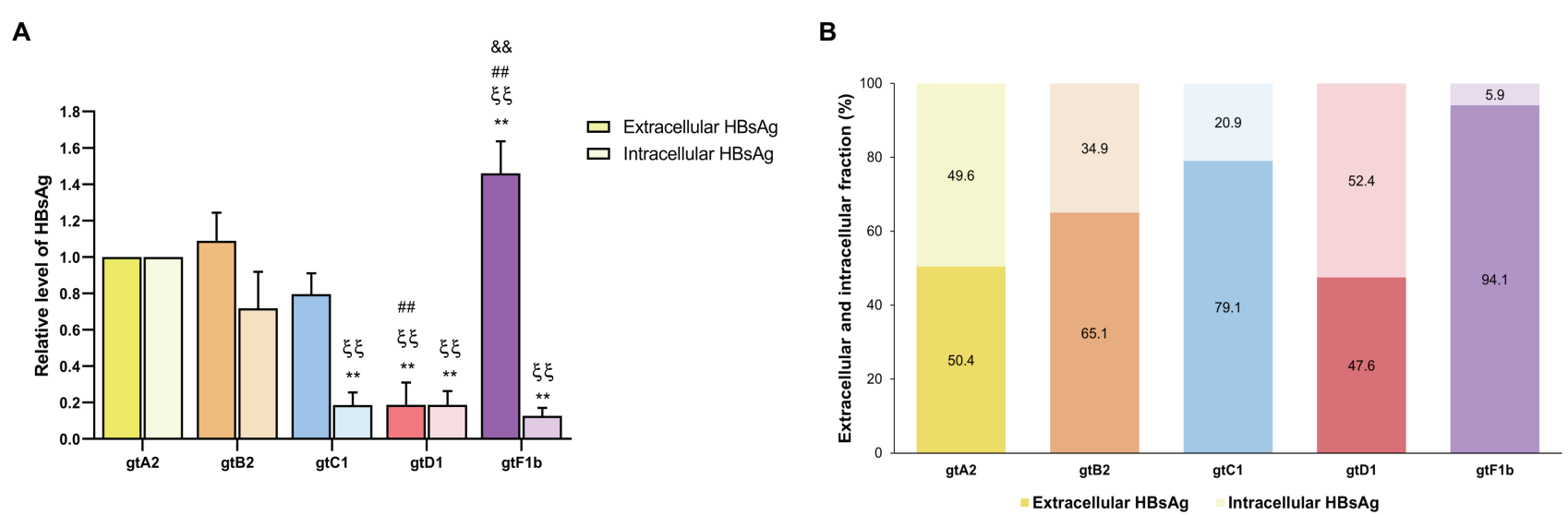

FIGURE 4 | Analysis of intracellular and secreted HBsAg levels across genotypes. HuH-7 cells were transfected with linear full-length HBV genomes of genotypes A2, B2, C1, D1, and F1b. Three days post-transfection, cells and culture supernatants were harvested, and intracellular and extracellular levels of HBsAg were determined by electrochemiluminescence immunoassay (A). Extracellular/intracellular HbsAg ratio (B). Values shown represent the mean \pm standard deviation of three independent experiments. *: Intracellular or extracellular difference in relation to genotype A2, $\xi$ : Intracellular or extracellular difference in relation to genotype B2, \#: Intracellular or extracellular difference in relation to genotype gtC1 and \&: Intracellular or extracellular difference in relation to genotype D1. Two symbols: $p<0.0001$. 
A

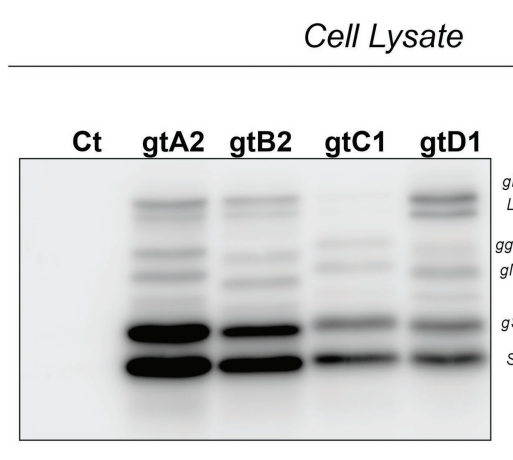

Cell Lysate

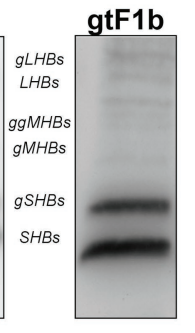

\section{$\beta$-actin}
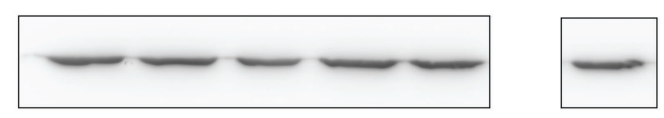

B

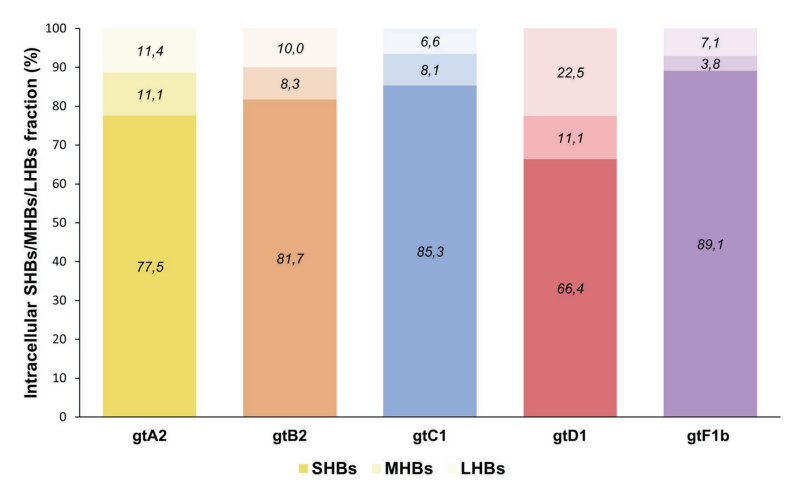

c

\section{Supernatant}

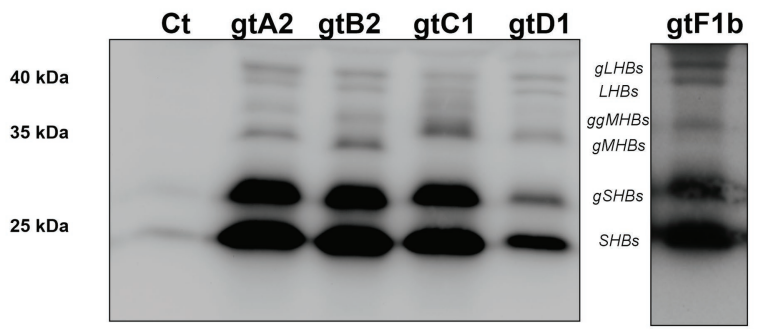

FIGURE 5 | Relative composition of HBsAg proteins among genotypes. HuH-7 cells were transfected with linear full-length HBV genomes of genotypes A2, B2, C1, D1, and F1b. Three days post-transfection, cellular lysates (A) and the corresponding culture supernatants (B) were analyzed by Western Blot, using a SHBs specific monoclonal (HB01) antibody. As this antibody shows a decreased reactivity for HBsAg derived from genotype $F$ transfected cells, an increased time of exposure was needed. SHBs and LHBs occur in unglycosylated (LHBs and SHBs) and glycosylated (gLHBs and gSHBs) forms, while MHBs occurs in glycosylated (gMHBs) and double glycosylated (ggMHBs) forms (C) Intracellular and (D) extracellular LHBs/MHBs/SHBs ratio was determined. Ct: cell transfected with pUC19 empty vector (control).
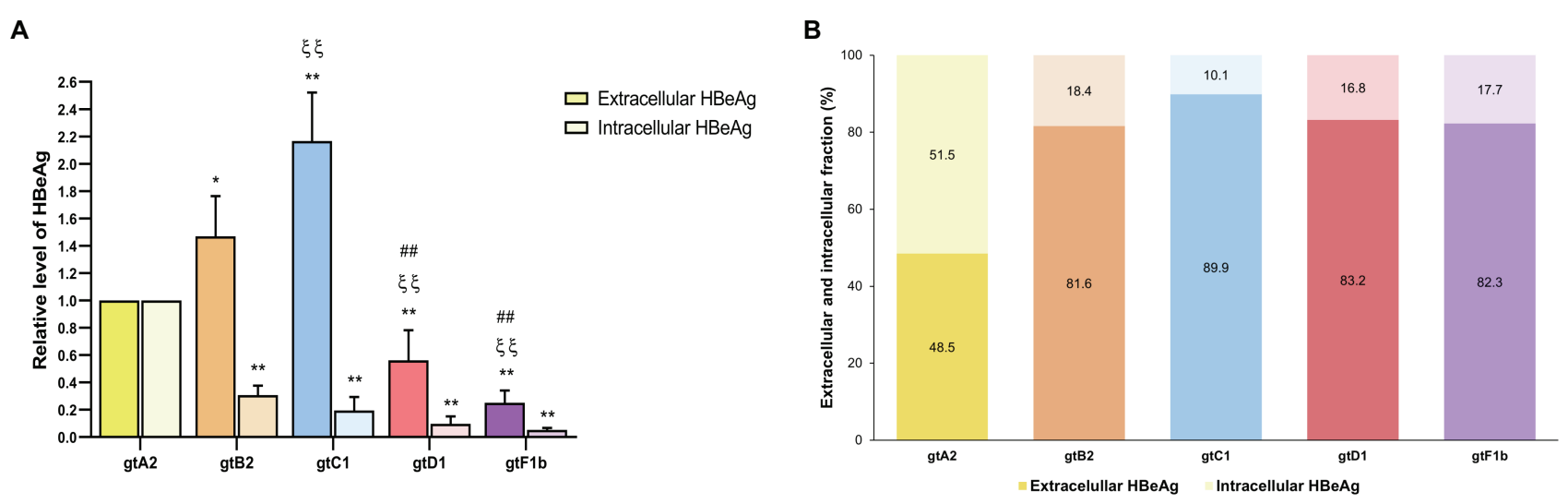

FIGURE 6 | Analysis of intracellular and secreted HBeAg levels across genotypes. HuH-7 cells were transfected with linear full-length HBV genomes of genotypes A2, B2, C1, D1, and F1b. Three days post-transfection, cells and culture supernatants were harvested, and intra- and extracellular levels of HBeAg were determined by ECLIA (A). Extracellular/intracellular HBeAg ratio (B). Shown values represent the mean \pm standard deviation of three independent experiments. *: Intracellular or extracellular difference in relation to genotype A2, $\xi$ : Intracellular or extracellular difference in relation to genotype B2, and \#: Intracellular or extracellular difference in relation to genotype gtC1. One symbol: $p<0.005$ and two symbols: $p<0.0001$. 
TABLE 1 | Viral replication and protein expression levels of each genotype.

\begin{tabular}{|c|c|c|c|c|c|}
\hline & \multicolumn{5}{|c|}{ Genotype } \\
\hline & A2 & B2 & C1 & D1 & F1b \\
\hline $\begin{array}{l}\text { cccDNA } \\
\text { (Copies/cell) }\end{array}$ & 2.73 & $4.71^{* *}$ & $3.34^{\xi}$ & $3.13^{\xi}$ & $5.34^{* * \# \# \& \&}$ \\
\hline $\begin{array}{l}\text { pgRNA } \\
(\text { Copies/ } / \text { l) }\end{array}$ & $9.31 \times 10^{2}$ & $9.32 \times 10^{4 * *} \xi \xi$ & $4.1 \times 10^{4 * * \xi \xi}$ & $3.58 \times 10^{4 * *} \xi \xi$ & $6.58 \times 10^{4 * * \xi \xi \xi \# \& \&}$ \\
\hline 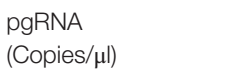 & $1.02 \times 10^{5}$ & $3.48 \times 10^{2 * *}$ & $6.25 \times 10^{3 \star \star}$ & $5.02 \times 10^{4 * * * \xi \xi \# \# ~}$ & $1.54 \times 10^{4 * * * \xi \xi \# \# \& \&}$ \\
\hline $\begin{array}{l}\text { Intracellular DNA } \\
(\mathrm{OD})\end{array}$ & $3.89 \times 10^{3}$ & $1.15 \times 10^{4 * *}$ & $2.38 \times 10^{3 \xi \xi}$ & $7.16 \times 10^{3 * *} \xi \xi \# \#$ & $8.44 \times 10^{3 * * * \xi \xi \# \# ~}$ \\
\hline $\begin{array}{l}\text { Extracellular DNA } \\
(\text { Copies } / \mu l)\end{array}$ & $6.59 \times 10^{5}$ & $7.38 \times 10^{5}$ & $4.74 \times 10^{5 \xi}$ & $6.59 \times 10^{5}$ & $5.47 \times 10^{5}$ \\
\hline $\begin{array}{l}\text { Extracellular HBsAg } \\
(\mathrm{IU} / \mathrm{ml})\end{array}$ & 99.7 & 108.67 & 79.76 & $18.94^{* *} \xi_{\xi} \# \#$ & $145.56^{* * *} \xi_{\xi} \# \# \& \&$ \\
\hline $\begin{array}{l}\text { Intracellular HBsAg } \\
(\mathrm{IU} / \mathrm{ml})\end{array}$ & 95.9 & 69.04 & $18.22^{* * \xi \xi}$ & $18.21^{* * \xi \xi}$ & $12.47^{* * \xi \xi}$ \\
\hline $\begin{array}{l}\text { Extracellular HBeAg } \\
\text { (S/Co) }\end{array}$ & 26.3 & $38.66^{*}$ & $57.07^{* * * \xi \xi}$ & $14.73^{* * \xi \xi 乡 \# ~}$ & $6.58^{* * * \xi \xi * * * \xi \xi \#}$ \\
\hline $\begin{array}{l}\text { Intracellular HBeAg } \\
\text { (S/Co) }\end{array}$ & 27.9 & $8.65^{* *}$ & $5.52^{* * *}$ & $2.76^{* *}$ & $1.47^{* *}$ \\
\hline
\end{tabular}

Shown values represent the mean of three independent experiments. *, difference in relation to gtA2; $\xi$, difference in relation to gtB2; \#, difference in relation to gtC1 and \&, difference in relation to gtD1. One symbol: $p<0.005$ and two symbols: $p<0.0001$.

outcomes, response to antiviral treatments, progression of liver disease, among other features (Kim et al., 2011; Liu and Kao, 2013); however, the molecular basis or biological properties of the virus that support these differences have not yet been established.

High viral load levels and the HBeAg-positive stage have been identified as markers associated with the risk of liver disease progression. Likewise, the intracellular accumulation of viral proteins has been described as a direct mechanism of pathogenesis in chronic HBV infection (Seeger and Mason, 2015; Hadziyannis and Laras, 2018).

In the present study, we characterize the biological properties of HBV genotypes A2, B2, C1, D1, and F1b, identifying major differences in HBV replicative capacity and antigen expression across these genotypes.

Even though previous works have functionally characterized HBV genotypes (Sugiyama et al., 2006; Qin et al., 2011; Sozzi et al., 2016, 2018; Bannister et al., 2020), this is the first study to comparatively analyze the European (A and D) and Asian ( $\mathrm{B}$ and $\mathrm{C}$ ) genotypes with the indigenous American F genotype. Genotype F shows a wide distribution throughout the American continent and is the autochthonous strain in native communities from Central and South America, being also found in Alaska (Ledesma et al., 2015; Rodrigo et al., 2016; Mojsiejczuk et al., 2020). Therefore, the functional characterization of American (sub)genotypes and their comparison to genotypes circulating in other geographical regions would provide valuable information to try to understand the differences in $\mathrm{HBV}$ natural history observed across HBV (sub)genotypes.

In this study, we have used unit-length monomeric $\mathrm{HBV}$ genomes, which represent a more reliable transfection system to study HBV replicative capacity across genotypes. Previous studies comparing the biological properties of genotypes have used more than unit-length constructs, which may influence the replication capacity and antigen expression of HBV genotypes (Bhoola et al., 2014; Wose Kinge et al., 2020). Even though this is a more robust system, promoting high levels of HBV replication and protein expression, the enhancer I/II and the Core promoter regions that regulate the transcription of pgRNA and Precore mRNA, are duplicated. In addition, more than unit-length HBV constructs are directly transcribed in the cell nucleus regardless of the formation of cccDNA (Amir et al., 2019). Therefore, these features may alter the biological properties of the constructs, which is unsuitable for evaluating differences in $\mathrm{HBV}$ replication among genotypes.

In the present study, we showed significant differences in HBV replication capacity among genotypes, being higher in genotype B2, followed by genotypes F1b and D1, whereas genotypes $\mathrm{A} 2$ and $\mathrm{C} 1$ showed the lowest replication capacity. These findings are consistent with those of Qin et al., who identified a higher replication capacity for genotype B2 in relation to genotype $\mathrm{C}$ after transfecting $\mathrm{HuH}-7$ cells with circularized HBV genomes (Qin et al., 2011). In contrast, other studies have shown higher replication rates for genotypes A2, C2, and D3 compared to genotype B2 (Sozzi et al., 2016) or higher rates for genotype C compared to genotypes B2 and A2 (Sugiyama et al., 2006) following transfection of $\mathrm{HuH}-7$ cells with 1.3- or 1.24-fold copy of the HBV genome, respectively. These controversial results might be a consequence of the different experimental systems used in the studies, as well as the subgenotypes utilized, since dissimilar biological characteristics have been described even between subgenotypes of the same genotype (Bhoola and Kramvis, 2016; Khatun et al., 2018; Elizalde et al., 2019). 
The uneven replicative capacity among genotypes observed in this work might contribute to explain the clinical differences observed across HBV (sub)genotypes. On the one hand, genotypes $\mathrm{A}$ and $\mathrm{C}$ have been associated with a higher progression to chronic infection in relation to genotypes $\mathrm{D}$ and $\mathrm{B}$, respectively (Sumi et al., 2003; Chu and Liaw, 2005; Liu and Kao, 2013). The low replicative activity of these genotypes might contribute to the immune response evasion, favoring the persistence of the infection. On the other hand, genotype B has been associated with fulminant hepatitis and acute liver failure (Ozasa et al., 2006; Ren, 2010). The intracellular accumulation of replicative intermediates in genotype $B$ infected patients might provoke a more vigorous though short-lived immune clearance phase which could trigger fulminant hepatitis and liver failure. However, extrapolation of results from in vitro experimental models directly to the clinic should be done with caution.

The Core promoter plays a key role in $\mathrm{HBV}$ replication and morphogenesis, directing the transcription of both pgRNA and Precore mRNA (Quarleri, 2014). The specific detection and quantification of these transcripts revealed striking differences among genotypes. In genotypes A2 and D1, the Core promoter activity is diverted to the production of Precore mRNA, whereas in genotypes B2, C1, and F1b, the activity of the Core promoter is biased to the production of pgRNA. In vitro analysis of mutants of this region has established that the Core promoter contains cis-acting elements that independently direct the transcription of pgRNA and Precore mRNA. These two elements overlap slightly yet are genetically distinct (Chen et al., 1995; Günther et al., 1997). In addition, it has been shown that several transcriptional factors bind to these regulatory elements and differentially regulate the synthesis of pgRNA and Precore mRNA (Yu and Mertz, 1997; Zheng et al., 2004; Meier-Stephenson et al., 2018). Sequence analysis of the Core promoter region revealed high levels of sequence variability across genotypes (range from 6 to $15 \%$ of divergence). The imbalance in the transcription of the RNAs regulated by the Core promoter may be a consequence of the sequence variability across genotypes, causing a differential binding of transcription factors in these two regulatory regions.

Paradoxically, while lower levels of cccDNA, pgRNA, and intracellular HBV DNA were detected for genotypes A2 and $\mathrm{C} 1$ in relation to genotypes $\mathrm{B} 2$ and $\mathrm{F} 1 \mathrm{~b}$, similar levels of extracellular DNA were observed in all genotypes. These findings are in line with previous studies that showed a lower replication level, but a higher virion secretion capacity for genotype $\mathrm{C}$ in relation to genotype B (Qin et al., 2011), suggesting that the low replication capacity combined with the efficient virion secretion for genotype $\mathrm{C}$ would lead to the rapid spread of the virus without eliciting a strong immune response, contributing to persistent infections.

Furthermore, after pgRNA is encapsidated and retrotranscribed into rcDNA form, immature capsids can be enveloped and released from the infected hepatocytes as virions or, alternatively, recycled back into the nucleus, to maintain the reservoir of cccDNA. Our results suggest that genotypes B2 and F1b might favor the recycling path, increasing the cccDNA pool over virion secretion; meanwhile, genotypes $\mathrm{A} 2$ and $\mathrm{C} 1$ would favor the secretion of the viral particles. This supports the comparable levels of extracellular HBV DNA despite the observed differences in cccDNA levels among genotypes.

The analysis of antigen expression and secretion also revealed remarkable differences among genotypes. Overall, the different genotypes expressed comparable levels of total HBsAg, except for genotype D1, which synthesized substantial lower levels of the antigen. Similar findings were also described in several in vitro studies (Sugiyama et al., 2006; Sozzi et al., 2016; Hassemer et al., 2017; Zhang et al., 2017), as well as in the serum of patients infected with different $\mathrm{HBV}$ genotypes (Brunetto et al., 2013; Riveiro-Barciela et al., 2017; Salpini et al., 2020). HBsAg expression is regulated by two distinct promoters: Surface promoter I (SPI) regulates the transcription of the 2.4-kb mRNA that encodes the LHBs protein, and surface promoter II (SPII) is responsible for the 2.1-kb mRNA transcription, which directs the translation of MHBs and SHBs. A previous study comparing the SPI and SPII promoter activities between genotypes A and D revealed a weaker SPII promoter activity in genotype $\mathrm{D}$, whereas the activity of the SPI promoter did not show differences between the two genotypes (Zhang et al., 2017). The weaker SPII promoter activity observed in genotype $\mathrm{D}$ might be responsible for the reduced $\mathrm{HBsAg}$ production observed in this genotype.

Furthermore, we have observed striking differences in the extra- and intracellular distribution of HBsAg. Genotypes A2 and D1 retained around 50\% of the expressed antigen, and genotypes $\mathrm{B} 2$ and $\mathrm{C} 1$ showed intermediate levels of retention, while nearly all HBsAg was secreted for genotype F1b. As a whole, these results indicate that besides the levels of expression, different factors affect $\mathrm{HBsAg}$ secretion. In this regard, the ratio between the different forms of HBsAg is one of the best characterized factors that influence the secretion of HBsAg. It has been shown that HBsAg composition shows specific patterns at different stages of the natural history of chronic infection, as well as high expression levels of LHBs have been associated with intracellular antigen retention (Churin et al., 2015; Pfefferkorn et al., 2018; Lin et al., 2020). This was observed in genotype $\mathrm{D} 1$, in which LHBs/MHBs represent $33.6 \%$ of the total HBsAg. However, in genotype A2, where almost $50 \%$ of the antigen is retained, the amount of LHBs and MHBs represents $13.5 \%$ of the total HBsAg. Therefore, other factors might be involved in the intracellular retention of the antigen. In addition, it has been shown that intracellular accumulation of HBsAg triggers a sustained endoplasmic reticulum (ER) overload response, leading to ER oxidative stress, metabolic switching, and genomic instability which are associated with a pro-oncogenic effect (Li et al., 2019; Lin et al., 2020). Therefore, the intracellular accumulation of HBsAg may play a role in inducing liver damage, in particular for genotypes A2 and D1 where half of the expressed antigen is intracellularly accumulated.

Finally, marked differences were also observed in the levels of expression and secretion of HBeAg between the different genotypes. The highest levels were detected for genotype C1, despite its low replication rate, and the lowest for genotypes D1 and F1b. These findings are in line with a recent study by Cooper et al. that showed significantly higher levels of 
quantitative $\mathrm{HBeAg}$ in serum samples of patients chronically infected with genotype $\mathrm{C}$ in relation to genotypes $\mathrm{B}, \mathrm{A} 1$, and D (Cooper et al., 2021). Interestingly, the expression levels of $\mathrm{HBeAg}$ do not strictly correlate with those of Precore mRNA, which were higher for genotypes A2 and D1. Hence, other factors besides the Precore mRNA level appear to influence the HbeAg expression and secretion, as might be posttranslational modifications of p25 and p22 precursory Precore proteins.

Remarkably, as observed for HbsAg, genotype A2 retained intracellularly about $50 \%$ of the expressed HbeAg. It has been described that HbeAg has a dual function, circulating $\mathrm{HBeAg}$ (p17) plays an immunomodulatory role during the immunotolerant stage in the natural history of infection, modulating the host's immune response and contributing to the establishment of persistent viral infection, while cytosolic HBeAg (p22) mainly antagonizes the innate immune responses (Milich and Liang, 2003; Frelin et al., 2009; Milich, 2019). In this regard, previous works have shown that cytosolic $\mathrm{HBeAg}$ can suppress IL- $1 \beta$-mediated NF- $\kappa \mathrm{B}$ activation and impair JAK-STAT signaling leading to the repression of interferon action, providing a molecular mechanism that also promotes persistence of infection (Wilson et al., 2011; Mitra et al., 2019). Therefore, the intracellular retention of $\mathrm{HBeAg}$ detected in genotype A2 may contribute to counteract the immune pressure, thus favoring viral persistence in up to $10 \%$ of the adulthood infection (Kobayashi et al., 2002; Suzuki et al., 2005; Nabuco, 2012).

\section{CONCLUSION}

This study provides new insights into the biological characteristics of HBV genotypes. The replicative capacity and antigen expression of the most prevalent European, Asian, and American genotypes

\section{REFERENCES}

Amir, F., Siddiqui, Z. I., Farooqui, S. R., Anwer, A., Khan, S., Azmi, M. I., et al. (2019). Impact of length of replication competent genome of Hepatitis B Virus over the differential antigenic secretion. J. Cell. Biochem. 120, 17858-17871. doi: 10.1002/jcb.29054

Araujo, N. M., Teles, S. A., and Spitz, N. (2020). Comprehensive analysis of clinically significant Hepatitis B virus mutations in relation to genotype, Subgenotype and geographic region. Front. Microbiol. 11:616023. doi: 10.3389/ fmicb.2020.616023

Bannister, E., Sozzi, V., Mason, H., Locarnini, S., Hardikar, W., and Revill, P. A. (2020). Analysis of the in vitro replication phenotype of african Hepatitis B Virus (HBV) genotypes and subgenotypes present in Australia identifies marked differences in DNA and protein expression. Virology 540, 97-103. doi: 10.1016/j.virol.2019.11.001

Bhoola, N. H., and Kramvis, A. (2016). Hepatitis B e antigen expression by Hepatitis B virus Subgenotype A1 relative to Subgenotypes A2 and D3 in cultured hepatocellular carcinoma (HUH7) cells. Intervirology 59, 48-59. doi: $10.1159 / 000446240$

Bhoola, N. H., Reumann, K., Kew, M. C., Will, H., and Kramvis, A. (2014). Construction of replication competent plasmids of Hepatitis B Virus Subgenotypes A1, A2 and D3 with authentic endogenous promoters. J. Virol. Methods 203, 54-64. doi: 10.1016/j.jviromet.2014.03.015 were comprehensively compared, identifying marked differences in viral replication and protein expression that might contribute to understand the differential role of genotypes in clinical outcomes, progression of liver disease, $\mathrm{HBeAg}$ seroconversion rates, and the emergence of mutation profiles.

\section{DATA AVAILABILITY STATEMENT}

The raw data supporting the conclusions of this article will be made available by the authors, without undue reservation.

\section{AUTHOR CONTRIBUTIONS}

ME performed the experiments, analyzed the data, and drafted the manuscript. LT and LM contributed to the conduction of experiments. ME, JQ, RC, and DF participated in the conception, drafting, and/or editing of the manuscript. All authors have read and agreed to the published version of the manuscript.

\section{FUNDING}

This work was supported by grants from Consejo Nacional de Investigaciones Científicas y Técnicas (CONICET) [PIP11220080101169], and Universidad de Buenos Aires UBACyT [20020170100206BA 2018-2021], PIDAE [2019-3473].

\section{SUPPLEMENTARY MATERIAL}

The Supplementary Material for this article can be found at: https://www.frontiersin.org/articles/10.3389/fmicb.2021.758613/ full\#supplementary-material

Brunetto, M. R., Marcellin, P., Cherubini, B., Yurdaydin, C., Farci, P., Hadziyannis, S. J., et al. (2013). Response to peginterferon alfa-2A (40KD) in hbeag-negative $\mathrm{CHB}$ : on-treatment kinetics of hbsag serum levels vary by HBV genotype. J. Hepatol. 59, 1153-1159. doi: 10.1016/j. jhep.2013.07.017

Caballero, A., Tabernero, D., and Buti, M., ans Rodriguez-Frias, F.. (2018). Hepatitis B virus: the challenge of an ancient virus with multiple FACES AND A remarkable replication strategy. Antivir. Res. 158, 34-44. doi:10.1016/j. antiviral.2018.07.019.

Chen, I. H., Huang, C. J., and Ting, L. P. (1995). Overlapping initiator and TATA box functions in the basal core promoter of hepatitis B virus. J. Virol. 69, 3647-3657. doi: 10.1128/jvi.69.6.3647-3657.1995

Ching, L. K., Gounder, P. P., Bulkow, L., Spradling, P. R., Bruce, M. G., Negus, S. et al. (2016). Incidence of hepatocellular carcinoma according to hepatitis B virus genotype in Alaska native people. Liver Int. 36, 1507-1515. doi: 10.1111/liv.13129

Chu, C. M., and Liaw, Y. F. (2005). Genotype c hepatitis b virus infection is associated with $\mathrm{A}$ higher risk of reactivation of hepatitis $\mathrm{B}$ and progression to cirrhosis than genotype b: A longitudinal study of Hepatitis B e antigenpositive patients with normal aminotransferase levels at bas. J. Hepatol. 43, 411-417. doi: 10.1016/j.jhep.2005.03.018

Churin, Y., Roderfeld, M., and Roeb, E. (2015). Hepatitis B Virus large surface protein: Function and Fame. Hepatobiliary Surg. Nutr. 4, 1-10. doi: 10.3978/j. issn.2304-3881.2014.12.08 
Cooper, S. L., King, W. C., Mogul, D. B., Ghany, M. G., Schwarz, K. B., Lau, D. T., et al. (2021). Clinical significance of quantitative e antigen in A cohort of Hepatitis B virus-infected children and adults in North America. J. Viral Hepat. 28, 1042-1056. doi: 10.1111/jvh.13520

Elizalde, M. M., Speroni, M., Campos, R. H., and Flichman, D. M. (2019). Hepatitis B Virus X gene differentially modulates subgenotype F1b and F4 replication. Viruses 11:655. doi: 10.3390/v11070655

Frelin, L., Wahlström, T., Tucker, A. E., Jones, J., Hughes, J., Lee, B. O., et al. (2009). A mechanism to explain the selection of the hepatitis e antigenNEGATIVE mutant during chronic hepatitis b virus infection. J. Virol. 83, 1379-1392. doi: 10.1128/JVI.01902-08

Günther, S., Sommer, G., Iwanska, A., and WILL, H. (1997). Heterogeneity and common features of defective Hepatitis B Virus genomes derived from spliced pregenomic RNA. Virology 238, 363-371. doi: 10.1006/viro.1997.8863

Hadziyannis, E., and Laras, A. (2018). Viral biomarkers in chronic HbeAg negative HBV infection. Genes 9, 1-20. doi: 10.3390/GENES9100469

Hassemer, M., Finkernagel, M., Peiffer, K. H., Glebe, D., Akhras, S., Reuter, A., et al. (2017). Comparative characterization of Hepatitis B Virus surface antigen derived from different Hepatitis B Virus genotypes. Virology 502, 1-12. doi: 10.1016/j.virol.2016.12.003

Khatun, M., Mondal, R. K., Pal, S., Baidya, A., Bishnu, D., Banerjee, P., et al. (2018). Distinctiveness in virological Features and pathogenic potentials of subgenotypes D1, D2, D3 and D5 of Hepatitis B Virus. Sci. Rep. 8:8055. doi: 10.1038/S41598-018-26414-4

Kim, B. K., Revill, P. A., and Ahn, S. H. (2011). HBV genotypes: relevance to natural history, pathogenesis AND treatment of chronic hepatitis b. Antivir. Ther. 16, 1169-1186. doi: 10.3851/IMP1982

Kobayashi, M., Arase, Y., Ikeda, K., Tsubota, A., Suzuki, Y., Saitoh, S., et al. (2002). Viral genotypes and response to interferon in patients with acute prolonged hepatitis b virus infection of adulthood in Japan. J. Med. Virol. 68, 522-528. doi: 10.1002/jmv.10239

Kock, J., Baumert, T. F., Delaney, W. E., Blum, H. E., and von Weizsacker, F. (2003). Inhibitory effect of Adefovir and lamivudine on the initiation of hepatitis b virus infection in primary tupaia hepatocytes. Hepatology 38, 1410-1418. doi: 10.1016/j.hep.2003.09.009

Kramvis, A. (2014). Genotypes and genetic variability of Hepatitis B Virus. Intervirology 57, 141-150. doi: 10.1159/000360947

Laras, A., Koskinas, J., Dimou, E., Kostamena, A., and Hadziyannis, S. J. (2006). Intrahepatic levels and replicative activity of covalently closed circular hepatitis b virus DNA in chronically infected patients. Hepatology 44, 694-702. doi: 10.1002/hep.21299

Laras, A., Koskinas, J., and Hadziyannis, S. J. (2002). In vivo suppression of precore mRNA synthesis is associated with mutations in the Hepatitis B virus core promoter. Virology 295, 86-96. doi: 10.1006/viro.2001.1352

Ledesma, M. M. G. L., Mojsiejczuk, L. N., Rodrigo, B., Sevic, I., Mammana, L., Galdame, O., et al. (2015). Hepatitis B Virus genotype distribution and genotype-specific $\mathrm{BCP} /$ precore substitutions in acute and chronic infections in Argentina. PLoS One 10:e0121436. doi: 10.1371/JOURNAL.PONE.0121436

Li, Y., Xia, Y., Cheng, X., Kleiner, D. E., Hewitt, S. M., Sproch, J., et al. (2019). Hepatitis B surface antigen activates unfolded protein response in forming ground glass hepatocytes of chronic Hepatitis B. Viruses 11, 1-17. doi: 10.3390/V11040386

Lin, W. L., Hung, J. H., and Huang, W. (2020). Association of the Hepatitis B Virus large surface protein with viral infectivity and endoplasmic reticulum stress-mediated liver carcinogenesis. Cells 9:2052. doi: 10.3390/ cells 9092052

Liu, C. J., and Kao, J. H. (2013). Global perspective on the natural history of chronic hepatitis b: role of Hepatitis B virus genotypes A to J. Semin. Liver Dis. 33, 97-102. doi: 10.1055/s-0033-1345716

Marchio, A., Cerapio, J. P., Ruiz, E., Cano, L., Casavilca, S., Terris, B., et al. (2018). Early-onset liver cancer in south America associates with low Hepatitis B Virus DNA burden. Sci. Rep. 8:12031. doi: 10.1038/S41598-018-30229-8

McNaughton, A. L., Revill, P. A., Littlejohn, M., Matthews, P. C., and Ansari, M. A. (2020). Analysis of genomic-length HBV sequences to determine genotype and subgenotype reference sequences. J. Gen. Virol. 101, 271-283. doi: 10.1099/jgv.0.001387

Meier-Stephenson, V., Bremner, W., Dalton, C., van Marle, G., Coffin, C., and Patel, T. (2018). Comprehensive analysis of Hepatitis B Virus promoter region mutations. Viruses 10, 1-13. doi: 10.3390/V10110603
Milich, D. R. (2019). Is the function of the HBEAG really unknown? Hum. Vaccines Immunother. 15, 2187-2191. doi: 10.1080/21645515.2019.1607132

Milich, D., and Liang, T. J. (2003). Exploring the Biological basis of Hepatitis B e antigen in Hepatitis B Virus infection. Hepatology 38, 1075-1086. doi: 10.1053/jhep.2003.50453

Mitra, B., Wang, J., Kim, E. S., Mao, R., Dong, M., Liu, Y., et al. (2019). Hepatitis B Virus Precore Protein P22 Inhibits alpha Interferon signaling by blocking stat nuclear translocation. J. Virol. 93, 1-20. doi: 10.1128/ JVI.00196-19

Mojsiejczuk, L., Torres, C., Flichman, D., and Campos, R. H. (2020). Longterm evolution of Hepatitis B Virus genotype F: strong association between viral diversification and the prehistoric settlement of central and South America. J. Viral Hepat. 27, 620-630. doi: 10.1111/jvh.13273

Nabuco, L. C. (2012). Hepatitis B Virus Genotypes in Southeast Brazil and its relationship with histological features. Mem. Inst. Cruz. 107, 758-789. doi: 10.1590/S0074-02762012000600013

Ozasa, A., Tanaka, Y., Orito, E., Sugiyama, M., Kang, J. H., Hige, S., et al. (2006). Influence of genotypes and precore mutations ON FULMINant or chronic outcome of acute Hepatitis B Virus infection. Hepatology 44, 326-334. doi: 10.1002/hep.21249

Pfefferkorn, M., Böhm, S., Schott, T., Deichsel, D., Bremer, C. M., Schröder, K., et al. (2018). Quantification of large AND middle proteins of hepatitis $b$ virus surface antigen (HBSAG) as A novel tool for the identification of inactive HBV carriers. Gut 67, 2045-2053. doi: 10.1136/gutjnl-2017-313811

Pineau, P., Ruiz, E., Deharo, E., and Bertani, S., (2018). On hepatocellular carcinoma in South America and early-age onset of the disease. Clin. Res. Hepatol. Gastroenterol. 43, 522-526. doi: 10.1016/J.CLINRE.2018.10.019

Qin, Y., Tang, X., Garcia, T., Hussain, M., Zhang, J., Lok, A., et al. (2011). Hepatitis B virus genotype $c$ isolates with wild-type core promoter sequence replicate less efficiently than genotype $b$ isolates but possess higher virion secretion capacity. J. Virol. 85, 10167-10177. doi: 10.1128/JVI.00819-11

Quarleri, J. (2014). Core promoter: A critical region where the Hepatitis B virus makes decisions. World J. Gastroenterol. 20, 425-435. doi: 10.3748/ wjg.v20.i2.425

Ren, X. (2010). Hepatitis b virus genotype and basal core promoter/precore mutations are associated with hepatitis b-related acute-on-chronic liver failure without pre-existing liver cirrhosis. J. Viral Hepat. 17, 887-895. doi: 10.1111/j. 1365-2893.2009.01254.x

Riveiro-Barciela, M., Bes, M., Rodríguez-FRÍAS, F., Tabernero, D., Ruiz, A., Casillas, R., et al. (2017). Serum Hepatitis B Core-related antigen is more accurate THAN Hepatitis B surface antigen to identify inactive carriers, regardless of hepatitis b virus genotype. Clin. Microbiol. Infect. 23, 860-867. doi: 10.1016/j.cmi.2017.03.003

Rodrigo, M. B., Mojsiejczuk, L. N., Torres, C., and Sevic, I. (2016). Analysis of the molecular evolution of Hepatitis B Virus genotypes in symptomatic acute infections in argentina. PLoS One 11:e0159509. doi: 10.1371/JOURNAL. PONE.0159509

Salpini, R., Battisti, A., Piermatteo, L., Carioti, L., Anastasiou, O. E., Gill, U. S., et al. (2020). Key mutations in the C-terminus of the Hbv surface glycoprotein correlate with lower Hbsag levels in vivo, hinder Hbsag secretion in vitro and reduce Hbsag structural stability in the setting of Hbeag-Negative chronic Hbv genotype-D infection. Emerg. Microbes Infect. 9, 928-939. doi: 10.1080/22221751.2020.1757998

Seeger, C., and Mason, W. S. (2015). Molecular Biology of Hepatitis B Virus infection. Virology 480, 672-686. doi: 10.1016/J.VIROL.2015.02.031

Shi, W., Zhang, Z., Ling, C., Zheng, W., Zhu, C., Carr, M. J., et al. (2013). Hepatitis B virus subgenotyping: History, effects of recombination, misclassifications, and corrections. Infect. Genet. Evol. 16, 355-361. doi: 10.1016/j.meegid.2013.03.021

Sozzi, V., Shen, F., Chen, J., Colledge, D., Jackson, K., Locarnini, S., et al. (2018). In vitro studies identify a low replication phenotype for Hepatitis $\mathrm{B}$ virus genotype $\mathrm{h}$ generally associated with occult $\mathrm{HBV}$ and less severe liver disease. Virology 519, 190-196. doi: 10.1016/j.virol.2018.04.015

Sozzi, V., Walsh, R., Littlejohn, M., Colledge, D., Jackson, K., Warner, N., et al. (2016). in vitro studies show that sequence variability contributes to marked variation in Hepatitis B virus replication, protein expression, and function observed across genotypes. J. Virol. 90, 10054-10064. doi: 10.1128/JVI.01293-16

Sugiyama, M., Tanaka, Y., Kato, T., Orito, E., Ito, K., Acharya, S. K., et al. (2006). Influence of Hepatitis B Virus genotypes on the intra- and extracellular 
expression of viral dna and antigens. Hepatology 44, 915-924. doi: 10.1002/ hep. 21345

Sumi, H., Yokosuka, O., Seki, N., Arai, M., Imazeki, F., Kurihara, T., et al. (2003). Influence of Hepatitis B Virus genotypes on the progression of chronic type B liver disease. Hepatology 37, 19-26. doi: 10.1053/ jhep.2003.50036

Suzuki, Y., Kobayashi, M., Ikeda, K., Suzuki, F., Arfase, Y., Akuta, N., et al. (2005). Persistence of acute infection with hepatitis b virus genotype A and treatment in Japan. J. Med. Virol. 76, 33-39. doi: 10.1002/jmv.20320

Tong, S., and Revill, P. (2016). Overview of Hepatitis B viral replication and genetic variability. J. Hepatol. 64, S4-S16. doi: 10.1016/j.jhep.2016.01.027

Tsukuda, S., and Watashi, K. (2020). Hepatitis b Virus Biology and life cycle. Antivir. Res. 182, 104925. doi: 10.1016/j.antiviral.2020.104925

Velkov, S., Ott, J., Protzer, U., and Michler, T. (2018). The Global hepatitis B virus genotype distribution approximated from available genotyping data. Genes. 9:495. doi: 10.3390/GENES9100495

WHO Hepatitis B (2017). Hepatitis B Fact Sheet, In: World, Health, Organisation (Eds.).

Wilson, R., Warner, N., Ryan, K., Selleck, L., Colledge, D., Rodgers, S., et al. (2011). The Hepatitis B e antigen suppresses IL-1B-mediated NF-KB activation in hepatocytes. J. Viral Hepat. 18, e499-e507. doi: 10.1111/J. 1365-2893.2011.01484.X

Wose Kinge, C. N., Bhoola, N. H., and Kramvis, A. (2020). In vitro systems for studying different genotypes/sub-genotypes of Hepatitis B virus: strengths and limitations. Viruses 12:353. doi: 10.3390/v12030353

Yu, X., and Mertz, J. E. (1997). Differential regulation of the pre-c and pregenomic promoters of human hepatitis $b$ virus by members of the nuclear receptor superfamily. J. Virol. 71, 9366-9374. doi: 10.1128/ JVI.71.12.9366-9374.1997

Zhang, F., Tang, X., Garcia, T., Lok, A. S., Wang, Y., Jia, H., et al. (2017). Characterization of contrasting features between Hepatitis B virus genotype a and genotype $\mathrm{d}$ in small envelope protein expression and surface antigen secretion. Virology 503, 52-61. doi: 10.1016/j.virol.2017.01.009

Zheng, Y., Li, J., and Ou, J. H. (2004). Regulation of Hepatitis B virus core promoter by transcription factors HNF1 and HNF4 and the viral $\mathrm{x}$ protein. J. Virol. 78, 6908-6914. doi: 10.1128/JVI.78.13.6908-6914.2004

Conflict of Interest: The authors declare that the research was conducted in the absence of any commercial or financial relationships that could be construed as a potential conflict of interest.

Publisher's Note: All claims expressed in this article are solely those of the authors and do not necessarily represent those of their affiliated organizations, or those of the publisher, the editors and the reviewers. Any product that may be evaluated in this article, or claim that may be made by its manufacturer, is not guaranteed or endorsed by the publisher.

Copyright (C) 2021 Elizalde, Tadey, Mammana, Quarleri, Campos and Flichman. This is an open-access article distributed under the terms of the Creative Commons Attribution License (CC BY). The use, distribution or reproduction in other forums is permitted, provided the original author(s) and the copyright owner(s) are credited and that the original publication in this journal is cited, in accordance with accepted academic practice. No use, distribution or reproduction is permitted which does not comply with these terms. 